\title{
Optimal Designing of Distribution Center Operation Process
}

\author{
Sun Jing ${ }^{1,2, *}$, Dong Shaohua ${ }^{1}$, Pang Hui ${ }^{1}$ and Liu Bo ${ }^{1}$ \\ ${ }^{I}$ School of Mechanical Engineering, University of Science and Technology Beijing, Beijing, 100083, P.R. China; \\ ${ }^{2}$ Department of Industrial Engineering and Logistics, Beijing Union University, Beijing, 100020, P.R. China
}

\begin{abstract}
This paper aims to introduce a method for better designing of Distribution Center operation process so as to increase the operation efficiency at lower cost. Considering the current situation of a given Distribution Center, this paper designs the operation process and provides the layout chart based on a given number of equipment, operators and volume of goods, etc. Then the concrete actions included in each process step are analyzed, and the standard operation time of each action is calculated using MOST (Maynard Operations Sequence Technique) method. In the end, appropriate numbers of operators are assigned to each process step to ensure line balance. Proper implementation of the method introduced in this paper will bring benefits to corporations regarding to service quality and competitiveness.
\end{abstract}

Keywords: Distribution center, optimal designing, operation process.

\section{INTRODUCTION}

Distribution Center is an institution which receiving and handling the order information from terminal customers, sorting out various goods from upstream, picking and assembling goods according to the requirements of customer [1]. It solves the contradiction between diverse demands and massive manufacture, and it gradually becomes the symbol of modern logistics.

With rapidly development of our society, intensively rising orders propose higher requirement to operation process of Distribution Center [2,3]. In order to response swiftly and accurately to customer orders, reduce operation cost and improve service quality, modern Distribution Centers must have efficient and rationalized operation ability, scientific plan, efficient process and perfect management system [4]. All of these need that Distribution Centers have rational facility layout, normative procedure, fluent process and reasonable personnel assignment.

However, nowadays, many Distribution Centers rely greatly on manual labor rather than automation, and have lots of unreasonable operation process. This brings a certain loss to Distribution Centers and related supply chain system. For this reason, how to effectively design and optimize the operation process of Distribution Centers, improve the operation efficiency and deliver goods to customers rapidly has become the critical problem that must be solved [5].

The operation process of Distribution Center involves many actions. Each action needs a certain time to be done. These "simple" actions are worthy of optimizing in action design, sequence and standard time to meet the goal of rapidly assembling, sorting and delivering goods to customers.

\section{INTRODUCTION OF MOST}

MOST is a proprietary tool of H. B. Maynard \& Co. of USA. It studies process steps of human body and divides these process steps into different actions. It can predict process step time by determining time of each action. MOST has scientific calculating method and accurate result.

MOST can be used in many fields, such as assembly, knitting, sewing, machine tool, machine set-up, packing, shoe manufacturing, industrial processes, cargo handling, electronics, repair, maintenance, office operations, etc.

MOST is designed for intermediate short cycle assembly to intermediate long cycle operational work in a non-tointermediate repetitive environment. This is the environment that permits rating scale of 82 BSI (British Standards Institute) to 100BSI to be achieved under the condition of practice opportunity. MOST is a rating scale of 82BSI built into the PMTS (Predetermined Motion Time Standard) value. This value assumes that a qualified operator with the necessary training and practice would be able to achieve the time set from proper analysis of work methods.

\subsection{Functions of MOST}

The functions of MOST include:

1. Document the best method to do the job to provide standardized workmanship;

2. Eliminating waste from the workflow;

3. Plan production system and line setup in advance of implementation to do it right at the first time;

4. Schedule operators for work based on time taken and perform manning level at the appropriate level;

5. Forecast costs accurately for quotation and determine profit contribution in advance;

6. Determine compensation based on output produced; 
7. Manage performance for productivity gains;

8. Establish business goals by setting reasonable and achievable targets.

\subsection{Advantages of MOST}

MOST has many advantages:

1. Fast

2. Systematic

3. Accurate

4. Reduce user's Errors

5. Reduce paperwork

\subsection{Three Sequences}

MOST describes all manual work in three sequences:

\subsubsection{The General Move Sequence}

The general move sequence deals with the spatial displacement of an object. Under manual control, the object follows an unrestricted path through the air.

The general move sequence describes get, place and return. Fig. (1) shows this sequence.

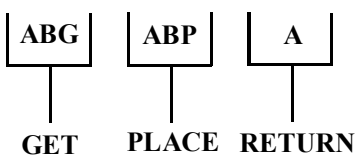

Fig. (1). The general move sequence.

In Fig. (1), every symbol is expressed as follows:

A---Action Distance

B---Body Motion

G---Gain Control

P---Place Motion

\subsubsection{The Controlled Move Sequence}

The controlled move sequence describes the manual displacement of an object over a controlled path. That is, the movement of the object is restricted in at least one direction by contact with or attachment to another object.

The controlled moves sequence describes get, move or actuate and return.

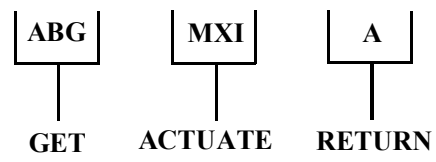

Fig. (2). The controlled move sequence.

Fig. (2) shows the controlled moves sequence, where,

A---Action Distance

B---Body Motion

G---Gain Control

M---Move Controlled, covers all manually guided movements or actions of an object over a controlled path
X---Process Time, occurs as that portion of work controlled by processes or machine and not by manual action

I---Align, refers to manual actions following the controlled move to achieve the alignment of objects

\subsubsection{The Tool Use Sequence}

The tool use sequence is a combination of general and controlled moves describing the actions performed with tools.

The tool use sequence describes get tool, place tool, use tool, aside tool and return, which is shown in Fig. (3).

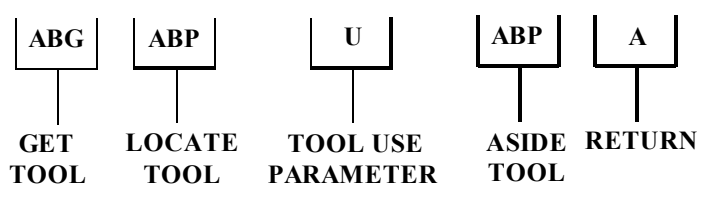

Fig. (3). The tool use sequence.

In Fig. (3),

A---Action Distance

B---Body Motion

G---Gain Control

P--- Place Motion

U---Tool Use Parameters (Fasten, Record, Loosen, Measure, Cut, Think, Surface Treat, etc.)

\subsection{MOST Index Value}

Different action has different index value.

Table 1 shows the index value of general move.

\subsection{Time Calculation}

The time measurement unit of MOST is TMU.

$1 \mathrm{TMU}=0.00001 \mathrm{hr}=0.0006 \mathrm{~min}=0.036 \mathrm{sec}$

The total number of TMU is equal to decuple sum of indexes. Multiplying this total number of TMU by 0.036 gives the total time.

Example:

Sequence: $\mathrm{A}_{6} \mathrm{~B}_{6} \mathrm{G}_{1} \mathrm{~A}_{6} \mathrm{~B}_{0} \mathrm{P}_{1} \mathrm{~A}_{0}$

Sum of indexes $=6+6+1+6+0+1+0=20$

Number of TMU $=20 \times 10=200$

Seconds $=200 \times 0.036=7.2 \mathrm{sec}$

\section{CASE ANALYSIS AND STUDY}

This paper takes a Distribution Center of a logistics company for example.

\subsection{Basic Data}

The basic data include:

1. Volume: the total number of parcels received is 3000 , including 600 large parcels and 2400 small parcels. On average, 20 small parcels are packed in a big bag, so there are 120 big bags in all; 
Table 1. The index value of general move.

\begin{tabular}{|c|c|c|c|c|}
\hline \multicolumn{5}{|c|}{ General Move } \\
\hline 0 & $\begin{array}{c}<2 \text { inches } \\
<5 \mathrm{~cm}\end{array}$ & & & Hold, Toss, Strike \\
\hline 3 & $1-2$ steps & Bend and arise $50 \%$ occ & $\begin{array}{l}\text { Non-simo, Heavy or bulky, Blind or ob- } \\
\text { structed, Disengage, Interlocked, Collect }\end{array}$ & $\begin{array}{l}\text { Adjustments, Light pressure, Joggle, } \\
\text { LF with intermediate moves }\end{array}$ \\
\hline 6 & $3-4$ steps & Bend and arise & & $\begin{array}{l}\text { Care or precision, Heavy pressure, } \\
\text { Blind or obstructed, Search, Select }\end{array}$ \\
\hline
\end{tabular}

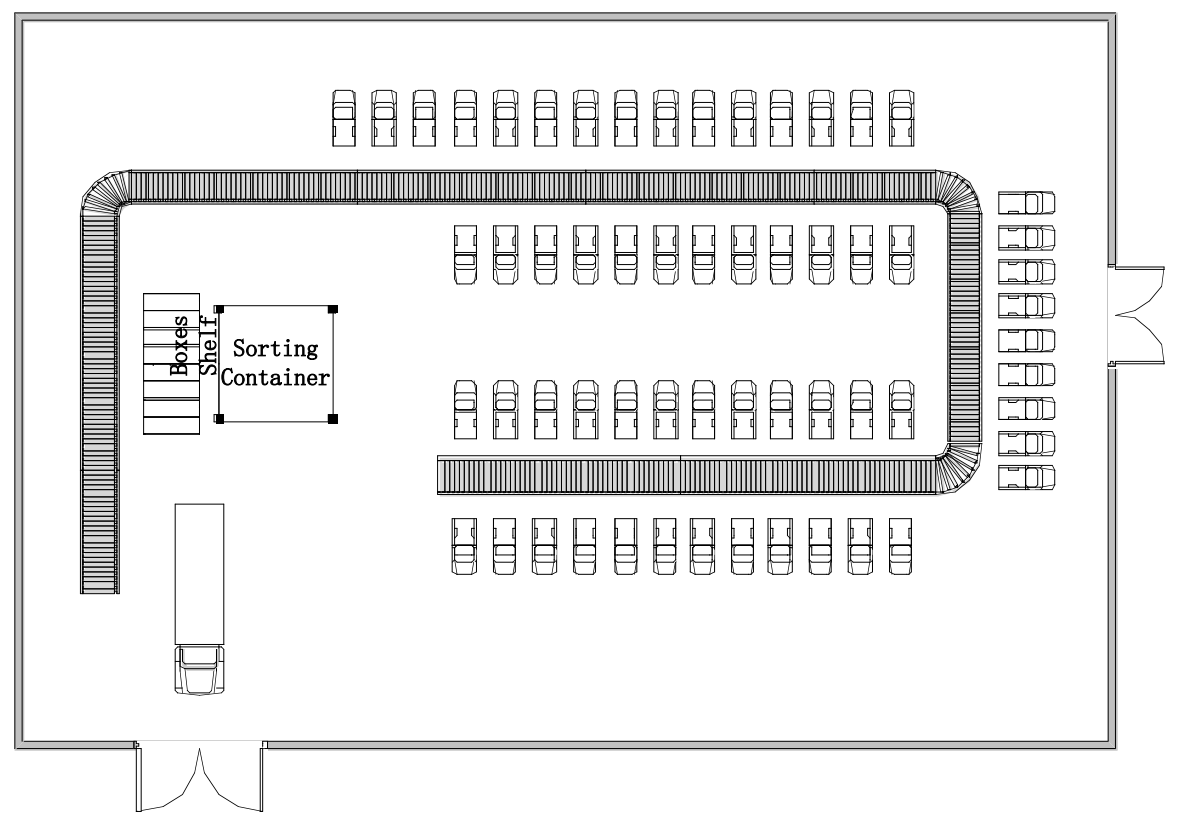

Fig. (4). The layout chart.

2. Operators: there are 60 operators, including 40 operators for handling parcels, 20 operators for sorting and loading;

3. Available equipment: 60 electric vehicle and 60 small boxes (each corresponding to a delivery area), one conveyor, one large sorting container, several scanners.

\subsection{Existing Problem}

There are some problems in this Distribution Center:

1. Many operations of this Distribution Center are not standardized. There are many irrational and inefficient operations and a lot of manual labor, such as: large repetitive manual labor because of unreasonable sorting operation designing; operators walking far distance due to irrational facility planning; too much useless actions like bending or turning around, increasing working intensity, wasting time and physical strength;

2. There are some bottlenecks in the whole operation process. The workloads of operators are unevenly;

3. Operators are unaware of the standard operation time and their performance. They are lack of working enthusiasm. The company's performance appraisal lacks standard operation time data.

\subsection{Optimal Designing of Operation Process}

According to current situation, the redesigned operation process can be generally described as:

1. Large parcels--- unload onto the conveyor, scan, code (according to delivery area), sort, load, scan; 
Table 2. Standard operation time of unloading large parcel.

\begin{tabular}{|c|c|c|c|}
\hline SQM & No. & Sequence Model & Total TMU \\
\hline \hline CM & 1 & A B G M X I A & \\
\hline & & 601 10 1 0 & 90 \\
\hline
\end{tabular}

Table 3. Standard operation time of scanning.

\begin{tabular}{|c|c|c|c|c|c|c|c|}
\hline SQM & No. & \multicolumn{5}{|c|}{ Sequence Model } & Total TMU \\
\hline $\mathrm{TU}$ & 1 & A B G & A B P & $\mathrm{R}$ & A B P & A & \\
\hline $\mathrm{R}$ & & 101 & 101 & 3 & 101 & 0 & 90 \\
\hline
\end{tabular}

Table 4. Standard operation time of coding.

\begin{tabular}{|c|c|c|c|c|c|c|}
\hline \multirow{2}{*}{$\begin{array}{c}\text { SQM } \\
\mathrm{TU}\end{array}$} & \multirow{2}{*}{$\begin{array}{c}\text { No. } \\
1\end{array}$} & \multicolumn{4}{|c|}{ Sequence Model } & \multirow[t]{2}{*}{ Total TMU } \\
\hline & & A B G & A B P & $\mathrm{T}$ & A B P & \\
\hline $\mathrm{TU}$ & 2 & A B G & A B P & $\mathrm{R}$ & A B P & \\
\hline
\end{tabular}

Table 5. Standard operation time of sorting and loading.

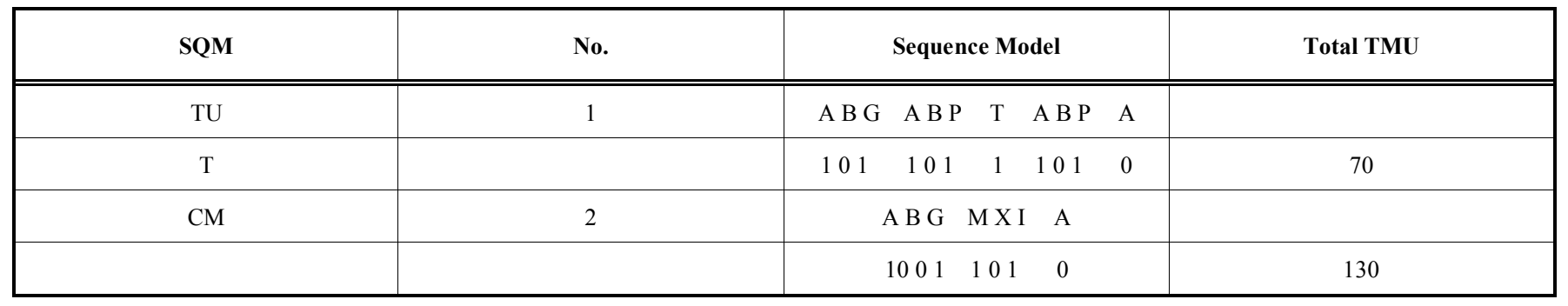

2. Small parcels--- scan bags, unload to sorting area, pour out small parcels into large sorting container, scan small parcels and put small parcels into boxes according to the destination and delivery area code marked on the boxes, carry boxes to conveyor, sort, load, scan.

\subsection{Drawing Layout Chart}

Considering the whole process, the facility layout chart can be drawn, which is shown in Fig. (4).

\subsection{Calculating Standard Operation Time}

\subsubsection{Calculating Standard Operation Time for Each Process Step of Large Parcels}

(1) Standard operation time of unloading each large parcel (Table 2)

This step means carrying large parcel from the truck to conveyor and then returning. The moving distance is 4 paces on average.

Total Seconds $=90 \mathrm{TMU}=90 \times 0.036=3.24 \mathrm{sec}$

(2) Standard operation time of scanning (Table 3 )
This step means scanning each large parcel with scanner.

Total Seconds $=90 \mathrm{TMU}=3.24 \mathrm{sec}$

(3) Standard operation time of coding (Table 4)

This step includes two actions: holding a parcel and reading address; writing delivery area code on it.

Delivery address generally includes 3 to 8 Chinese characters, and the corresponding index value $\mathrm{T}$ is 2 .

Delivery area code generally includes 3 figures, and the corresponding index value $\mathrm{R}$ is 4 .

Total Seconds $=180 \mathrm{TMU}=6.48 \mathrm{sec}$ 5)

(4) Standard operation time of sorting and loading (Table

This step includes two actions: finding parcel and holding by hands; carrying it from conveyor to vehicle and returning. The moving distance is 6 paces on average.

Delivery area code generally includes 3 figures, and the corresponding index value $\mathrm{T}$ is 1 .

Total Seconds $=200 \mathrm{TMU}=7.20 \mathrm{sec}$ 
Table 6. Standard operation time of unloading big bag.

\begin{tabular}{|c|c|c|c|}
\hline SQM & No. & Sequence Model & Total TMU \\
\hline \hline CM & 1 & A B G M X I A & \\
\hline & & 1601 1 01 A & 190 \\
\hline
\end{tabular}

Table 7. Standard operation time of pouring out small parcels.

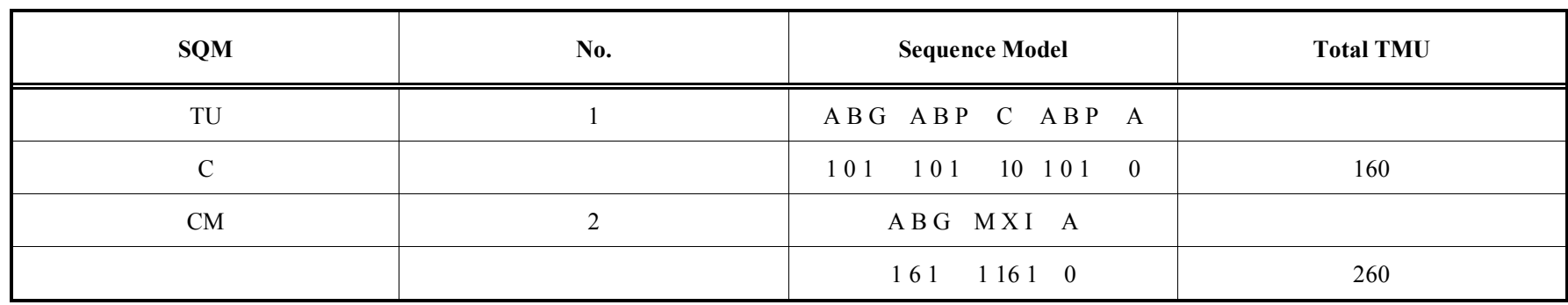

Table 8. Standard operation time of scanning and sorting.

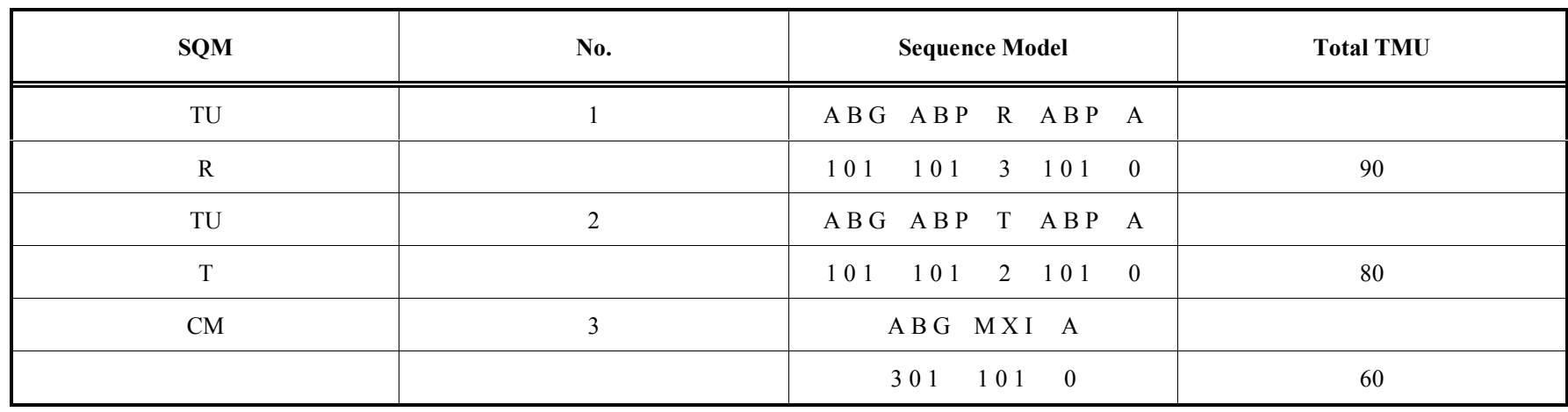

(5)Standard operation time of scanning after loaded (Table 3)

Total Seconds $=90 \mathrm{TMU}=3.24 \mathrm{sec}$

\subsubsection{Calculating Standard Operation Time for Each Process Step of Small Parcels}

(1) Standard operation time of scanning each big bag (Table 3)

Total Seconds $=90 \mathrm{TMU}=3.24 \mathrm{sec}$

(2) Standard operation time of unloading each big bag (Table 6)

This step means carrying big bag to sorting area and returning. The moving distance is 10 paces on average.

Total Seconds $=190 \mathrm{TMU}=6.84 \mathrm{sec}$

(3) Standard operation time of pouring out small parcels into large sorting container (Table 7)

This step includes two actions: cutting off the seal of big bag; lifting big bag and pouring out small parcels into sorting container.

The average speed of pouring out small parcels is 7 seconds per bag, and the corresponding index value $\mathrm{X}$ is 16 .

Total Seconds $=420 \mathrm{TMU}=15.12 \mathrm{sec}$
(4) Standard operation time of scanning each small parcel and sorting small parcel into box (Table 8)

This step includes three actions: scanning small parcel with scanner; picking up small parcel and reading address; putting small parcel into box.

Total Seconds $=230 \mathrm{TMU}=8.28 \mathrm{sec}$

(5) Standard operation time of carrying each box to conveyor (Table 9)

This step includes two actions: closing the box; carrying box to conveyor and returning. The moving distance is 8 paces on average.

Total Seconds $=230 \mathrm{TMU}=8.28 \mathrm{sec}$ 5)

(6) Standard operation time of sorting and loading (Table

This step includes two actions: finding box; carrying it from conveyor to vehicle and returning. The moving distance is 6 paces on average.

Total Seconds $=200 \mathrm{TMU}=7.20 \mathrm{sec}$

(7) Standard operation time of scanning after loaded (Table 3).

Total Seconds $=90 \mathrm{TMU}=3.24 \mathrm{sec}$ 
Table 9. Standard operation time of carrying box to conveyor.

\begin{tabular}{|c|c|c|c|}
\hline SQM & No. & Sequence Model & Total TMU \\
\hline \hline CM & 1 & A B G M X I A & \\
\hline CM & & 101 1 0 1 0 & 40 \\
\hline & 2 & A B G M X I A & \\
\hline
\end{tabular}

\subsection{Analyzing Line Balance and Assigning Operators}

In the whole operation process, 20 operators is charged for sorting, loading and scanning after loaded, and each operator charges 3 vehicles. These 20 operators do not need to be allocated by operation time. The rest 40 operators are disposable for other operations, and need to be allocated according to operation time ratio (the percentage of each operation time $v s$ the total time).

\subsubsection{Calculating the Total Time of Each Step}

(1) The total time of each process step of large parcel

unloading: $3.24 \times 600=1944 \mathrm{sec}$

Scaning: $3.24 \times 600=1944 \mathrm{sec}$

Codeing: $6.48 \times 600=3888 \mathrm{sec}$

(2)The total time of each process step of small parcel

Scanning big bags:3. $24 \times 120=388.8 \mathrm{sec}$

Unloading big bags: $6.84 \times 120=820.8 \mathrm{sec}$

Pouring out small parcels: $15.12 \times 120=1814.4 \mathrm{sec}$

Scanning and sorting small parcels: $8.28 \times 2400=19872 \mathrm{sec}$

Carrying boxes to conveyor: $8.28 \times 60=496.8 \mathrm{sec}$

All these process steps listed above need 31168.8 seconds.

\subsubsection{Calculating Operation Time Ratio}

(1) Unloading large parcels:

$1944 / 31168.8=0.062370062$

(2) Scanning large parcels:

$1944 / 31168.8=0.062370062$

(3) Coding large parcels:

$3888 / 31168.8=0.124740125$

(4) Scanning big bags:

$388.8 / 31168.8=0.012474012$

(5) Unloading big bags:

$820.8 / 31168.8=0.026334026$

(6) Pouring out small parcels:

$1814.4 / 31168.8=0.058212058$

(7) Scanning and sorting small parcels:

$19872 / 31168.8=0.637560638$
(8) Carrying boxes to conveyor:

$496.8 / 31168.8=0.015939016$

3.6.3. Calculating the Number of Operators in Each Process Step

(1) Unloading large parcels:

$0.062370062 \times 40 \approx 2.49$

(2) Scanning large parcels:

$0.062370062 \times 40 \approx 2.49$

(3) Coding large parcels:

$0.124740125 \times 40 \approx 4.99$

(4) Scanning big bags:

$0.012474012 \times 40 \approx 0.50$

(5) Unloading big bags:

$0.026334026 \times 40 \approx 1.05$

(6) Pouring out small parcels:

$0.058212058 \times 40 \approx 2.33$

(7) Scanning and sorting small parcels:

$0.637560638 \times 40 \approx 25.5$

(8) Carrying boxes to conveyor:

$0.015939016 \times 40 \approx 0.64$

3.6.4. Confirming the Number of Operators in Each Process Step

(1) Unloading large parcels: 2

(2) Scanning large parcels: 2

(3) Coding large parcels: 5

(4) Scanning big bags: 1

(5) Unloading big bags: 1

(6) Pouring out small parcels: 2

(7) Scanning and sorting small parcels: 26

(8) Carrying boxes to conveyor: 1

\section{SOME EXPLANATIONS}

\subsection{BSI}

The standard time calculated above is based on 82BSI, which is the qualified level. Multiplying this time by 0.82 gives time based on 100BSI, which is the positive level. It'd 
be better to tell operators about the time calculated by 100BSI and encourage them to reach this goal. This could be regarded as a performance appraisal index and reward system should be set correspondingly. In this way, operator's working enthusiasm will be inspired and the overall operation process will be optimized.

\subsection{The Functions of Scan}

Scanning plays an important role in Distribution Center operations [6]:

(1) Legal requirements. Customer's signature should be kept for 3-5 years;

(2) Customs declaration requirements. Used as the document support of electronic customs declaration;

(3) Traceability of responsibility. It is a way to trace down the process steps and operators in case the goods are lost or damaged. And it helps to improve the operator's sense of responsibility;

(4) Facilitating tracking logistics information. Customers are able to track the logistics information of their own goods. This promotes trust between customers and company.

\subsection{Parallel Problem}

Most operation process is actually going on parallel, that is, they process simultaneously. In fact, the operators of the front line can help the back line. Or the back line operators help the front line. In this way, operation time of each process step can be shorted, and higher efficient can be achieved $[7,8]$.

\section{THE SIGNIFICANCES OF APPLYING MOST IN DISTRIBUTION CENTERS}

MOST method is applied in this paper for optimal designing of Distribution Center operation process. Its significance lies in:

\subsection{Provides a Consist Guidance for Distribution Center Operation}

Without a uniform guidance, it will turn out that each operator operates in different ways at different times, and then ultimately influences the overall operation quality and efficiency. By clarifying the standard operation time for each process, operators can manage to accomplish their jobs, even transcending his goals. In this sense, the implementation of MOST in Distribution Centers provides a uniform guidance, which can motivate operators' working enthusiasm and keep optimizing the operation process.

\subsection{Guarantees Operational Quality of Distribution Cen- ters}

MOST is derived from constant summarizing, improving and optimizing during real operations. In this process, wisdom of many people and systematic scientific analyzing are incorporated. MOST is believed to be able to improve the operation quality dramatically.

The process optimization and operation standardization will minimize waste and avoid misoperation, especially after operators getting skilled. This ensures the Distribution Center operate at high quality.

\subsection{Enhances the Efficiency of Distribution Centers}

With each job quality improved, the whole operational efficiency will be prompted correspondingly.

MOST makes each operator clear about the time requirement and operation standard for each process step. This helps operators to minimize the time wasted by misoperation and enables them to evaluate their working efficiency by time index.

Through calculation of time and appropriate assignment of operators, the entire assembly line realizes balanced flow and eliminates the bottlenecks, which will inevitably save the whole process time and improve the working efficiency.

\subsection{Reduces the Operating Cost of Distribution Centers}

The operation optimization by MOST defines the demand of manpower so that the Distribution Center could cut off unnecessary workers and reduce labor cost. Besides, the balancing of operation line and removal of bottlenecks cut down the line waste, which lowers production cost. Both of them would reduce the overall operating cost and ensure the competitiveness of the Distribution Center.

In summary, the implementation of MOST brings enormous benefits to enterprises. For Distribution Centers with intensive work loads and higher demands for cost control, it is significant to apply MOST to set up standard operation time, optimize operation process and continuously improve afterwards to achieve lower cost and higher efficiency and keep competitiveness.

\section{CONCLUSION}

This paper analyzes the importance of operational optimization for Distribution Centers. It also introduces the concept of Distribution center and MOST method. Based on the actual data of orders, the number of operators and equipments, the operation process is designed and layout chart is made. The actions included in the operation process are listed and standard operation times are calculated using MOST method. And then the line balance is analyzed and appropriated number of operators is assigned. In this way, the overall operation efficiency is improved which helps the Distribution Center adapt to the competition of the future market.

The study in this paper can provide some valuable and meaningful references for academic researches and related enterprises in respect of optimization of operation process.

\section{CONFLICT OF INTEREST}

The authors confirm that this article content has no conflict of interest.

\section{ACKNOWLEDGEMENTS}

Jing Sun Author wishes to thank teachers in University of Science and Technology Beijing for their helpful suggestions and support. 


\section{REFERENCES}

[1] Y. P. Zhong, "How to improve the productivity of distribution center", Science and Technology Information, vol. 33, pp. 277, 2008.

[2] Y. Zhang, and J. G. Wei, "Global logistics' situation and chinese logistics' development", China Business and Market, vol. 23, pp. 30-33, 2009.

[3] J. Sun, and S. H. Dong, "Study on the delivery area optimization and management", Journal of Applied Sciences, vol. 13, no. 18, pp. 3730-3735, 2013.

[4] J. H. Son, and M. H. Kim, "Improving the performance of timeconstrained workflow processing", Journal of Systems and Software, vol. 58, no. 3, pp. 211-219, 2000.
[5] W. M. Wang, and W. Zheng, "Simulation and optimization of operating tactics in fruit and vegetable distribution center", Journal of Wuhan University of Technology (Information and Management Engineering), vol. 33, pp. 821-824, 2011.

[6] N. W. Zhou, "Application of RFID in distribution center processing”, Technology Wind, vol. 16, pp. 76-77, 2008.

[7] Y. Sun, and J. J. Zhang, "A method to solve cargo loading problem and VRP”, Logistics Management, vol. 2, pp. 83-87, 2012.

[8] W. L. Zheng, and H. Sun, "The strategy study for sorting operating system of distribution center", Journal of Guangdong Aib Polytechnic College, vol. 24, pp. 71-73, 2008.

Received: June 10, 2015

Revised: July 29, 2015

Accepted: August 15, 2015

(C) Jing et al.; Licensee Bentham Open.

This is an open access article licensed under the terms of the (https://creativecommons.org/licenses/by/4.0/legalcode), which permits unrestricted, noncommercial use, distribution and reproduction in any medium, provided the work is properly cited. 